Journal of Research in Interprofessional

Practice and

Education

Vol. 1.3

December, 2010

\title{
Designing and Operationalizing a Toolkit of Bilingual Interprofessional Education Assessment Instruments
}

\author{
Colla J. MacDonald, EdD; Douglas Archibald PhD(c), MA; \\ David L. Trumpower, PhD; Lynn Casimiro, PT, PhD; \\ Betty Cragg, RN, EdD; Wilma Jelley, PT, MEd
}

\begin{abstract}
This article addresses one of the most important unresolved issues of interprofessional education (IPE): assessment. Here we describe our process and experiences designing and operationalizing a toolkit of qualitative and quantitative IPE assessment instruments for online and face-to-face education programs developed concurrently in both English and French. The toolkit includes a) the quantitative $\mathrm{W}(\mathrm{e})$ Learn program evaluation survey, which aligns with the W(e)Learn framework, b) the quantitative Interprofessional Collaborative Competencies Attainment Survey (ICCAS), to self-assess competency development in collaborative practice using a post-post design, and c) qualitative team and learner contracts, with explanatory exemplars, that serve as both learning and assessment tools. These instruments are currently undergoing validation in hopes of a) increasing the likelihood that IPE experiences are planned and delivered effectively and b) increasing the justification and accountability of IPE experiences and practical outcomes. Although this validation process will continue for some time, the development of the IPE assessment tools is worthy of particular attention in order to guide further work in this field.

1---French and Enrglishtreopies of the tookkit assessments can be-downloaded from 'http://ennovativesolution.com/WeLearn/IPE-Instruments.html: Although these instruments were designed with interprofessional healthcare teams in mind, we feel they could readily be transferable to a variety of interdisciplinary tasks and settings, such as social work and human services education.
\end{abstract}

Keywords: Interprofessional education; Healthcare; Toolkit; Survey; Learner contract

\section{Introduction}

Interprofessional education (IPE) entails engaging professionals to learn with, from, and about each other in order to work more effectively in teams. Although this article addresses interprofessional healthcare education, we feel the processes and products described can be applied to a variety of interdisciplinary tasks and settings, such as social work and human services education.

Education and training can teach methods and approaches to increase clinical

Journal of Research in Interprofessional Practice and Education (JRIPE)

Vol. 1.3

(c) 2010

Corresponding author:

Colla MacDonald 'cjmacdon@@uottawa.cai capacity for interprofessional care (IPC), optimize the use of staff expertise and skills, improve communication among healthcare professionals, and increase the efficiency of case management $[1,2]$. Researchers have argued that "by learning and working together in educational settings, healthcare professionals will be able to work more effectively with one another in occupational settings" [3]. Barr [4] proposed that IPE is fundamental to a more efficient and effective healthcare system and, ultimately, better patient care. 
Designing and operationalizing a toolkit

MacDonald, Archibald, Trumpower, Casimiro, Cragg, \& Jelley

Journal of Research in Interprofessional Practice and Education

Vol. 1.3

December, 2010
Journal of Research in Interprofessional Practice and Education

In 2005 and 2006, Health Canada distributed \$20 million to 20 learning projects to develop IPE programs in various healthcare settings. An analysis of the 20 projects' evaluation plans [5] highlighted the following:

- the need for a variety of evaluation instruments and outcome measures to capture the range of experiences, contexts, and audiences, with sensitivity to cultural and local situations;

- the need for validated evaluation instruments that allow comparisons across projects; and

- the need to create support for evaluating IPE in order to continue to improve interprofessional education.

The purpose of this project (funded by Health Force Ontario) was to design, develop, pilot, refine, and begin psychometric testing of a toolkit of qualitative and quantitative instruments to assess IPE. The instruments within the toolkit were developed by the research team and are grounded in the IPE core competencies [11]. We are now gathering evidence regarding the validity of inferences that can be generated by these instruments with participants from various formal and informal IPE learning experiences. We currently have participants from across Canada, the United States, and New Zealand.

In this article we share these instruments to increase a) the likelihood that IPE experiences are planned and delivered effectively and b) the justification and accountability for interprofessional healthcare educational experiences and clinical practice. The validation process will require well over 1000 end users and could take another year or more to complete. Meanwhile, we have chosen to make these instruments readily available so that others may benefit and also participate in the validation of these products, if they choose to contact us.

\section{Methodology}

\section{An over-arching evaluation approach}

Freeth and Reeves [6] modified the work of Biggs [7] to create an approach to evaluate IPE. They suggested evaluation should focus on the presage (context in which learning occurs), the process (planning and delivery), and the product (collaborative competencies of IPE). In the creation of the IPE assessment instruments our focus was on the latter two aspects of the Freeth and Reeves 3P model: two qualitative, formative assessments to evaluate the process of IPE; and two quantitative surveys assessing the program and outcomes of IPE. In addition, Freeth, Hammick, Koppel, Reeves, and Barr [8] in their critical review of IPE called for more interpretive qualitative and comprehensive mixed methods studies. We anticipate our toolkit of validated assessment instruments will facilitate future research in the evaluation of IPE innovation.

\section{Designing the toolkit of evaluation instruments}

The initial drafts of the instruments were designed by an educator who specializes in program evaluation, a research assistant, and a statistician. The intention was to 
306

Designing and operationalizing a toolkit

MacDonald, Archibald, Trumpower, Casimiro, Cragg, \& Jelley

Journal of Research in Interprofessional Practice and Education

Vol. 1.3

December, 2010 create qualitative and quantitative instruments that would complement each other and, together with other tools currently being developed in colleagues' complementary research projects (rubric, Team Objective Structured Clinical Exam [TOSCE], professionalism checklist), provide a comprehensive evaluation of all aspects of any IPE course or program. The four instruments included in this research project are: 1) a quantitative survey designed to assess the effectiveness of a program's structure, content, delivery, service, and outcomes and align with the W(e)Learn framework (refer to Appendix A);2) a quantitative survey designed to assess changes in attitudes and behaviours that occur as a result of the IPE experience; 3 ) a qualitative team contract and 4) learner contract, each with explanatory exemplars, that serve as both formative learning and assessment tools (for the participant and the facilitator). We will now outline our general development process and then describe the specific development of each of the four instruments.

\section{General development process}

Several meetings were held over a three-month period with the initial team of three investigators to design the instruments. In addition, much editing and revising of the instruments took place between meetings via email. When the original team of three had completed their initial revisions, they emailed the instruments to an extended team of investigators that included an additional four educators who were all in senior administrative positions (Director, School of Nursing; Director of interprofessional care [IPC] programs at a local hospital; and two other IPE educators and supporters), who were also all healthcare professionals. A series of additional meetings occurred over another three-month period as each item on each instrument was carefully scrutinized for meaning, language interpretation, and relevance. When the team was satisfied with the content of the instruments, they were professionally formatted.

Since Canada has two official languages and the University of Ottawa is bilingual, the instruments were sent out to two different translators to be translated into French. When the translations were received, they were compared for accuracy by the francophone healthcare experts on the team and each item was selected and/or revised to represent the most comprehensive way of expressing the item while aligning with and reflecting the same meaning as the English version.

To further improve content validity, a broader group of subject matter experts (SMEs) was invited to review the instruments in both French and English. Nine anglophone SMEs were invited to participate in the English meetings, and four francophone SMEs were invited to participate in the French meetings. The SMEs were chosen based on their expertise in IPE and IPC, with an effort to represent a wide range of healthcare professions (medicine, speech language pathology, nursing, physiotherapy, occupational therapy, and pastoral care). The meetings with the francophone SMEs were held first. During three four-hour meetings, every item of each instrument (French version) was displayed sequentially on a large viewing screen and edited as a group for meaning, language, and relevance. One of the researchers made edits on the screen so that all of the SMEs could see and approve. Another 
307

Designing and operationalizing a toolkit

MacDonald, Archibald, Trumpower, Casimiro, Cragg, \& Jelley

Journal of Research in Interprofessional Practice and Education

Vol. 1.3 December, 2010 researcher and research assistant then translated the changes into English and revised the English versions of the instruments accordingly. The revised instruments (English version) were then sent to the anglophone SMEs for review before their meeting. The review process was similar to the meetings with the francophone SMEs, except that a single four-hour session proved adequate to revise the English versions of the instruments. The revised English and French versions of the instruments were then compared and modified by the bilingual SMEs until they felt the content was equivalent. The revised sets of instruments were then reviewed by all the bilingual researchers.

The requirements of translation also helped to clarify the exact meaning of each item. The process pointed out and subsequently reduced ambiguity, helped clarify and simplify language, and resulted in an excellent check on quality. The same process could be readily implemented to translate the toolkit to other languages to broaden its use and include diverse populations.

\section{$\mathrm{W}(\mathrm{e})$ Learn assessment instrument development}

The 3P model [6] states the importance of considering the context of the programs, facilitator characteristics, learner characteristics, and approaches to teaching and learning, as well the knowledge, skills, and behaviours associated with the collaborative competencies. We chose the $\mathrm{W}(\mathrm{e})$ Learn framework $[9,10]$ to guide the development of our program evaluation survey as it addresses a number of factors mentioned in the 3P model, in addition to detailing the design, delivery, and evaluation of IPE. W(e)Learn outlines four critical dimensions of online IPE-structure, content, media, and service-and is grounded in socio-constructivist theories and interprofessionalism. W(e)Learn is intended to elicit four levels of outcomes, the pinnacle of which is organizational change toward interprofessional collaboration and interprofessional practice and a resulting improvement in care delivery that promotes patient well-being. W(e)Learn offers an emergent design process; throughout the design, development, and delivery of IPE, the process is continually evaluated so it can be adapted and improved as necessary.

Because our first quantitative assessment tool-the $\mathrm{W}(\mathrm{e})$ Learn program evaluation survey-was designed to align with the W(e)Learn framework (Appendix A), a large set of items was constructed to correspond to each of its components (structure, content, media, service, and outcomes). W(e)Learn addresses a number of factors within Freeth and Reeves' 3P model [6]: context of the program, facilitator characteristics, learner characteristics, and approaches to teaching and learning, as well as the knowledge, skills, and behaviours associated with the collaborative competencies.

Early in the development process, it was recognized that certain elements of the $\mathrm{W}(\mathrm{e})$ Learn framework address issues relevant to the design/development of IPE of which learners may not be explicitly aware. For example, under the structure component of the framework, it is suggested that IPE designers conduct learner and context analyses. It is unlikely that learners would be aware of whether or not such analyses had been undertaken, except insofar as the results of such analyses are communicated to learners through the delivery of their IPE. Because the W(e)Learn 
308

Designing and operationalizing a toolkit

MacDonald, Archibald, Trumpower, Casimiro, Cragg, \& Jelley

Journal of Research in Interprofessional Practice and Education

Vol. 1.3

December, 2010 assessment instrument is intended to assess the learners' perceptions of their IPE experience, any items specific to the design/development of the IPE program that would be difficult for learners to discern were deleted.

After initial revisions, items intended to assess each of the following components of the W(e)Learn model were retained: structure (including facilitation strategies, pedagogical strategies, interactivity, and community), content (including inclusivity, authenticity, and responsiveness to stakeholder's needs), service (including that provided by the facilitator, the learner's organization, and other resources), and outcomes (including learner satisfaction, gains in knowledge and skill, and attitude change). Further revisions were then made to improve the clarity and conciseness of the wording of items and to make sure that it was consistent with current IPE terminology and core competencies. Also, as the instrument is intended to be used with a battery of instruments, an effort was made to make the W(e)Learn instrument user-friendly by including no more than 30 items. This limit required identification and subsequent deletion of redundant items.

\section{Interprofessional Collaboration Competencies Attainment Survey (ICCAS) development}

The ICCAS was based on a recently devised set of interprofessional collaboration competencies by a number of internationally renowned IPE/IPC researchers from across Canada [9]. In the fall of 2008 when we began the design of these instruments, the competencies developed by Curran et al. [11,12]were the only known interprofessional collaboration competencies that had been developed concurrently in both French and English, were based on a systematic review of the literature, and had undergone content validation in both French and English through a PanCanadian Delphi process. Our research group felt that this set of competencies was the most comprehensive documentation available on which to base the development of the ICCAS and the learner contract.

Several commonly used evaluation instruments were examined for their relevance to the new IPE/IPC competencies, including the Interdisciplinary Education Perception Scale [13], Readiness for Interprofessional Learning Scale [14], and the Attitudes Toward Healthcare Teams Scale [15]. Several items from these instruments were used as a source of inspiration to devise a list of 28 items that aligned with the six core collaboration competencies: communication, collaboration, roles and responsibilities, collaborative patient/family-centred approach, conflict management/resolution, and team functioning. The ICCAS was eventually revised and reduced to 20 items.

Several studies assessing IPE found that although changes in knowledge and skill attainment have often been recorded, it has been difficult to find studies that have measured a significant improvement in attitude toward IPE [16-18]. Three explanations for the lack of improvement in attitude could be: a) learners are early adopters who volunteer to participate and already have a positive attitude toward IPE, thus rating themselves at the top end of the scale at pre-test, leaving little to no room for improvement in the post-test; b) learners respond to the questionnaires based on 
309

Designing and operationalizing a toolkit

MacDonald, Archibald, Trumpower, Casimiro, Cragg, \& Jelley

Journal of Research in Interprofessional Practice and Education

Vol. 1.3 December, 2010 what they believe are the acceptable answers in terms of interprofessional collaboration, rather than what their attitudes really are; or c) learners rate their attitudes toward interprofessional collaboration very highly in the pre-test based on a lack of understanding of the full extent of IPC, leaving, once again, little to no room for improvement in the post-test. To increase the sensitivity of the ICCAS, a "post-post test" design was created in which learners are asked after completion of an IPE program to reflect on both their current and prior level of competency regarding interprofessional collaboration. By asking learners to assess their change in level of competency following completion of IPE, it is expected that they will have a better understanding of the nuances of interprofessional collaborative competencies and therefore will be better able to identify any weaknesses that they may have had prior to completing IPE. We expect the post-post test design will provide a clearer indication of the learners' perspective on the development of their competencies.

\section{Learner and team contract development}

The contract is a qualitative learning/assessment tool that is also based on the interprofessional collaboration competencies [11] and is intended to complement the quantitative W(e)Learn Program evaluation and ICCAS attitude/behaviour surveys. The contract (initially intended for both team and individual learner use) was designed with a companion set of exemplars to assist learners or teams and facilitators to plan and assess their IPE learning experiences. The concept of a contract was borrowed from our experience with adult education where contracts have been established between the facilitator and learners to identify what the learner will learn (learning objectives) and how they will do so (learning strategies) in order to attain their goals (learning outcomes). We were also motivated by our experience in IPE learning situations where teams initially found it difficult to understand what IPE was, how they would design a team plan, and how to begin the process. By providing a contract to guide this process, and an exemplar consisting of possible objectives, sample strategies, and appropriate IPE language, learners may understand the IPE process sooner, internalize it, and make it their own. As educators, we have found learners feel more comfortable taking risks when they fully understand what is expected of them. Therefore, the more structure provided in the early stages of learning, the more comfortable learners feel, and the more creative they become.

The objective of the contract is: a) to document how the learner or team plans to develop the competencies and activities associated with interprofessional practice (IP) and b) to assist the learner or team in identifying and documenting IP learning outcomes. There are four columns in the contract. In column 1, the learner/team finds the core competencies of IP. In column 2, the learner/team will write the objectives to be attained related to each of the IP core competencies. This column should be completed before the learning activity begins. In column 3, the learner will outline strategies to meet the objectives. This column should be completed before the learning activity begins. In column 4, the learner will document any observations or evidence relating to the development of IP core competencies. This column should be completed one to four weeks after the learning activity. 
Designing and operationalizing a toolkit

MacDonald, Archibald, Trumpower, Casimiro, Cragg, \& Jelley

Journal of Research in Interprofessional Practice and Education

Vol. 1.3 December, 2010
The contracts and companion exemplars provide much-needed tools for learners and facilitators, as well as a qualitative assessment tool to complement the quantitative tools already described. In one of the research team meetings, it was decided that the contract and exemplars should become two instruments (one for individual learner use and one for team use) in order to meet the needs of all IPE learning situations (those that have assigned teams of learners and those that focus on individual learners).

This study is unique because a) all instruments are aligned with a Canadian, nationally validated set of IPE core competencies and an IPE framework (W(e)Learn), b) the post-post design of our quantitative ICCAS tool, we believe, will be sensitive to changes in IPE attitude and behaviour, and c) the learner contract is a teaching/learning tool to help teams or individual learners plan their learning and becomes a qualitative self-reflection assessment tool after learning.

\section{Validation method}

At an IPE conference on assessment in 2009, a presenter was bemoaning the fact that current attitude scales did not show any change in the pre-post test. In the discussion that followed one of the educators from this project informed the audience that we were developing a toolkit of IPE instruments and that one of the instruments would experiment with a post-post design to try to address this issue. Six members of the audience gave the educator their contact information and indicated an interest in becoming involved in the validation of the IPE assessment instruments. As the instruments were being developed, a letter of invitation was emailed to the six potential conference audience members who were located across Canada, the United States, and New Zealand. Through word of mouth and additional conference presentations, growing interest to participate in the study emerged. Response to the invitation to participate in the study has been overwhelmingly positive, as many programs revealed that they need and want assessment instruments for their IPE projects. The four instruments in both French and English were emailed to programs in October 2009, with a list of criteria that needed to be met in order to be involved in the study (refer to Appendix B). The criteria included completion of a brief (approximately 10 minute) survey providing a course description and feedback on the instruments. Programs were asked to provide an MS Excel template for each assessment instrument completed by learners within the programs to assist with validation. Ethics approval was obtained and confidentiality of the participants was ensured.

For their participation in the project, programs were promised an electronic version of the four final instruments (in either French or English or both), with a synopsis of the psychometric properties. Programs would also receive a small stipend (\$300.00 CAD) to be used as needed (e.g., to pay a research assistant to input data).

Data is presently being collected in all programs to further refine and evaluate evidence regarding validity of the instruments. Specifically, internal consistency of the resulting scales of the instruments will be assessed using Cronbach's alpha. Any scales with poor internal consistency (alphas $<.80$ ) will be subjected to classical 
311

Designing and operationalizing a toolkit

MacDonald, Archibald, Trumpower, Casimiro, Cragg, \& Jelley

Journal of Research in Interprofessional Practice and Education

Vol. 1.3 December, 2010 item analysis. Item-total correlations will be computed between individual item responses and respective total scale scores. Items with low item-total correlations will be discarded from their respective scale. This process will be repeated in an iterative fashion until scales display adequate internal consistency. Finally, construct validity will be assessed with confirmatory factor analysis.

\section{Conclusion}

IPE/IPC is not a passing trend-it is here to stay. In a public address, the editor of the Journal of Interprofessional Care stated that there has been a great deal of literature published over the last decade. However, many of the studies are descriptive in nature and have focused on individual teams or learning programs. Reeves indicated that there needs to be a movement toward studies that can be generalized so that the field can develop. For this to occur, projects need to involve larger sample sizes and use standardized instruments. It is our intention to develop the W(e)Learn and the ICCAS surveys, and the Learner and Team Contracts assessment instruments so they can be generalized for use in a variety of IPE contexts.

We hope learner and team contracts will help motivate learners to identify strategies to meet any IPE program objectives, identify and provide evidence (if any) of learning outcomes of the IPE program in the workplace, and act as a vehicle to stimulate conversation among team members.

Collecting both qualitative and quantitative data on a program provides triangulation of data permitting corroboration of program information. Our toolkit of assessment instruments are intended to complement one another when used in combination. For example, whereas the W(e) Learn tool is intended to assess the process (planning and delivery) of IPE, the ICCAS is intended to assess the product (collaborative competencies). Both instruments do so quantitatively by asking learners to report their perceptions of the IPE program and of their own knowledge growth. The learner/team contracts are intended to assess both the process and product of IPE qualitatively by asking learners to apply their knowledge of collaborative competencies. The $\mathrm{W}(\mathrm{e})$ Learn and the ICCAS instruments are currently being adapted to Global Health competencies and piloted as MA and $\mathrm{PhD}$ projects. The contract is also currently being adapted as a planning tool for a Family Medicine Residence Program. At present, we have limited our study to evaluate evidence regarding validity of individual instruments. However, there would be merit in conducting follow-up studies to examine the validity of inferences drawn from the entire battery of instruments to see if a combined approach leads to a more comprehensive understanding of IPE program function and success.

In summary, assessment is an important, and often overlooked, element in designing an IPE initiative. Carole Orchard and Ivy Oandasan noted, in a 2010 IPE Ontario Conference workshop that it is very hard to get consensus among program organizers around assessing learners of an IPE activity/program. These proposed instruments are intended to make the assessment process easier.Erench and English_copiesiof the toolkit assessments-can be downloaded from: inttp://ennovativesolution.com /WeLearn/IPE-Instruments.htmli. We feel the processes and products described in 
312

Designing and operationalizing a toolkit

MacDonald, Archibald, Trumpower, Casimiro, Cragg, \& Jelley

Journal of Research in Interprofessional Practice and Education

Vol. 1.3

December, 2010 this article could be readily transferable to a wide variety of interprofessional educational programs and interprofessional care tasks and settings.

\section{References}

1. Barr, H., Koppel, I., Reeves, S., Hammick, M., \& Freeth, D. (2005). Effective interprofessional education: Arguments, assumptions \& evidence. Malden, MA: Blackwell Publishing.

2. Reeves, S., Goldman, J., Sawatzky-Girling, B., \& Burton, A. (2008). Knowledge transfer and

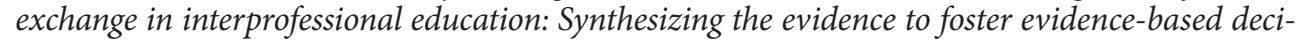

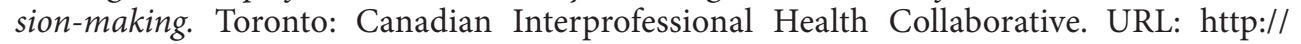
'www.cihc.ca/files/publications/The Evidence_For_IPE_July2008.pdf', [December 10, 2008].

3. Rice, A.H. (2000). Interdisciplinary collaboration in health care: Education, practice, and research. National Academies of Practice Forum, 2(1), 59-73.

4. Barr, H. (2002). Interprofessional education: Today, yesterday and tomorrow. A review commissioned by the Learning and Teaching Support Network for Health Sciences \& Practice. London: CAIPE.

5. MacDonald, C.J., Walton, R., \& Sun, R. (2008). Canadian Interprofessional Health Collaborative:

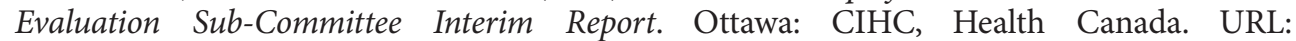
http://www.cihc.ca/files/publications/The_Evidence_For_IPE_July2008.pdff'_[November 12, 2008].

6. Freeth, D., \& Reeves, S. (2004). Learning to work together: Using the presage, process, product (3P) model to highlight decisions and possibilities. Journal of Interprofessional Care, 18(1), 43-56.

7. Biggs, J. (1993). From theory to practice: A cognitive systems approach. Higher Education Research and Development, 12, 73-85.

8. Freeth, D., Hammick, M., Koppel, I., Reeves, S., \& Barr, H. (2002). A critical review of evaluations of interprofessional education. London: Interprofessional Education Joint Evaluation Team (JET).

9. MacDonald, C.J., Stodel, E.J., Thompson, T-L., \& Casimiro, L. (2009). W(e)Learn: A framework for interprofessional education. International Journal of Electronic Healthcare, 5(1), 33-47.

10. Casimiro, L., MacDonald, C.J., Thompson, T-L., \& Stodel, E.J. (2009). Grounding theories of W(e)Learn : A framework for online interprofessional education, Journal of Interprofessional Care, 23(4), 390-400.

11. Curran, V.R., Casimiro, L., Banfield, V., Hall, P., Lackie, K. et al. (2009). Research for Interprofessional Competency-Based Evaluation (RICE), Journal of Interprofessional Care, 23(3), 297-300.

12. Curran, V., Casimiro, L., Banfield, V., Hall, P., Gierman, T., Lackie, K., Oandasan, I., Simmons, B., \& Wagner, S. (2010). Development and evaluation of an assessment rubric for measuring interprofessional collaborative competencies. (Report). Academic Health Council - Champlain region, Ottawa.

13. Luecht, R.M., Madsen, M.K., Taugher, M.P., \& Petterson, B.J. (1990). Assessing professional perceptions: Design and validation of an interdisciplinary education perception scale. Journal of Allied Health, 19(2), 181-191.

14. Parsell, G., \& Bligh, J. (1999). The development of a questionnaire to assess the readiness of health care students for interprofessional learning (RIPLS). Medical Education, 33(2), 95-100.

15. Heinemann, G.D., Schmitt, M.H., Farrell, M.P., \& Brallier, S.A. (1999). Development of an Attitude Toward Health Care Teams Scale. Evaluation and the Health Professions, 22, 123-142.

16. MacDonald, C.J., Archibald, D.B., Stodel, E.J., Chambers, L.W., \& Hall, P. (2008). Knowledge translation of interprofessional collaborative patient-centred practice. McGill Journal of Education, 43(3), 283-308.

17. MacDonald, C.J., Stodel, E.J., \& Casimiro, L. (2006). Online dementia care training for healthcare teams in continuing and long-term care homes: A viable solution for improving quality of care

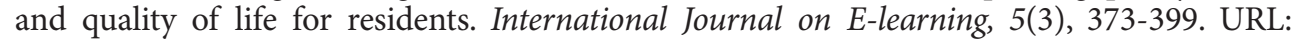
'http://_www.irrodl.org/index.php/irrodl/article/view/325/7444'[September 10, 2010].

18. MacDonald, C.J., Stodel, E.J., Hall, P., \& Weaver, L. (2009). The impact of an online learning resource designed to enhance interdisciplinary collaborative practice in palliative care: Findings from the Caring Together pilot project. Journal of Research in Interprofessional Practice and Education, 1(1), 42-66. 


\section{JRIPE}

313

Designing and operationalizing a toolkit

MacDonald, Archibald, Trumpower, Casimiro, Cragg, \& Jelley

Journal of Research in Interprofessional Practice and Education

Vol. 1.3

December, 2010

\section{Appendix A: W(e)Learn [10]}

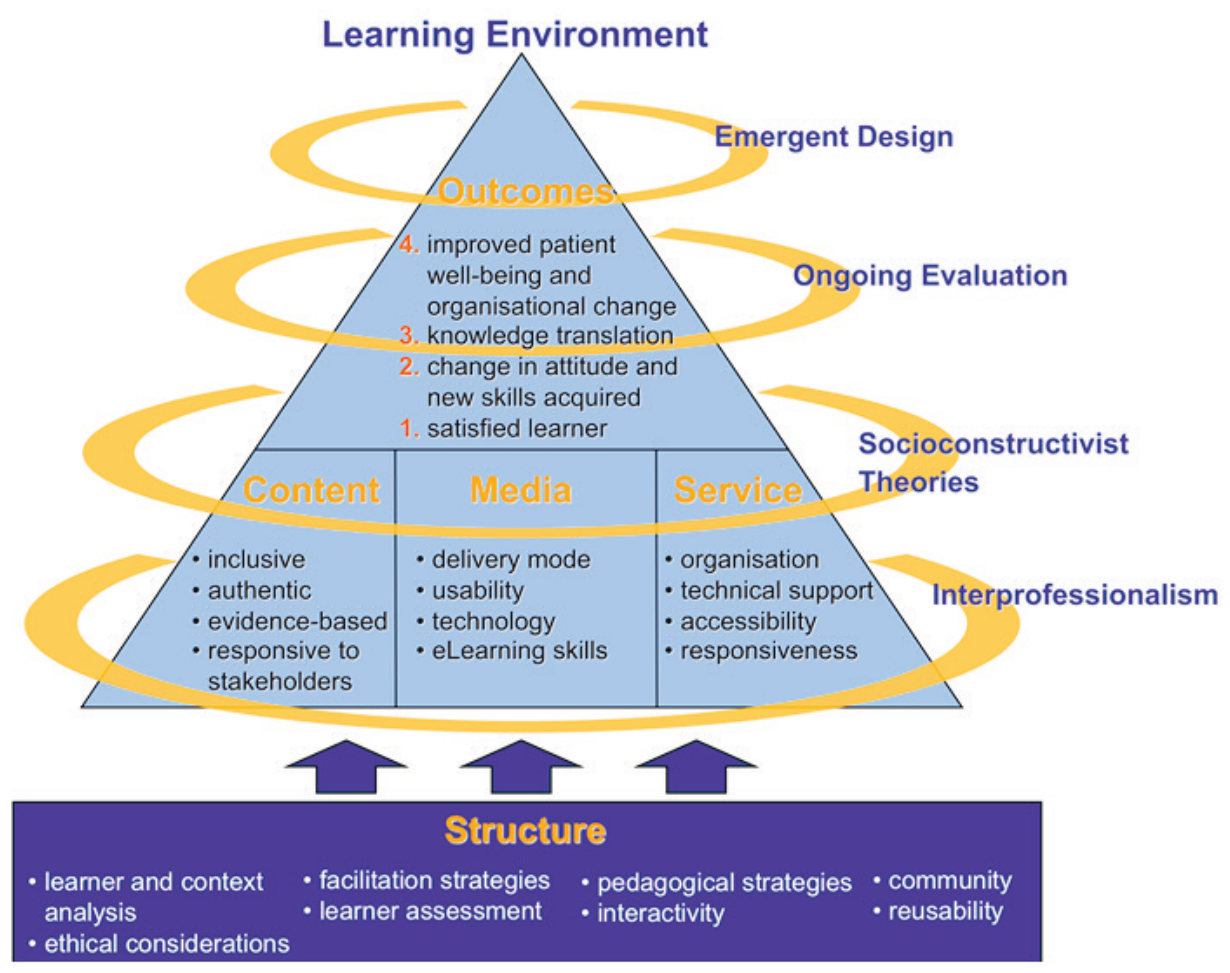

Appendix B: Letter of Invitation

Dear (type name),

Thank you for agreeing to participate in the validation study of our interprofessional education (IPE) assessment instruments. Enclosed you will find the IPE instruments, as well as a brief survey about your IPE program(s), a copy of our ethics approval letter, and an Excel file to be used for entering your data. A brief description of each enclosure is included at the end of this letter.

Your participation in the validation study involves the following steps:

1. Begin using the IPE instruments in your IPE program(s) at any time. You may choose to use the instruments in one program or in multiple programs. As well, you may choose to use all of the instruments or just a subset of them.

2. Enter the data that you collect with the IPE instruments into the enclosed Excel template. If you are using the instruments in multiple, distinct programs, please save the data from each program in a separate Excel file, and name each file using a unique label (e.g., If you are using the instruments in 2 different courses, you might name the Excel files with the associated course code: EDU5191.xls and EDU7395.xls). 


\section{JRIPE}

314

Designing and operationalizing a toolkit

MacDonald, Archibald, Trumpower, Casimiro, Cragg, \& Jelley
Journal of Research in Interprofessional Practice and Education

Vol. 1.3

December, 2010
Journal of Research in Interprofessional Practice and Education

3. Complete the Program Description and Instrument Feedback Survey. If you are using the instruments in multiple, distinct programs, please complete a separate survey for each, and be sure to include the program labels that you used for naming the associated Excel files.

4. Return the Excel data file(s) and the completed Program Description and Instrument Feedback Survey(s) to:

When we receive your data, we will send you a $\$ 300.00$ CAD stipend for your participation. If you use at least 3 of the IPE instruments (the ICCAS, W(e)Learn, and either the Team or Learner Contract) in your program we will send an additional $\$ 300$ CAD stipend. In order to receive the stipend and be included in the initial validation report, your data must be received before September 1st, 2010. After analyzing the data, we will send you our initial report on the psychometric properties of the instruments as well as revised instruments for your use.

If you have any questions about the process or about the instruments, we encourage you to contact us at. Again, we sincerely thank you for your participation.

Best wishes,

\section{ICCAS - Interprofessional Collaborative Competencies Attainment Survey}

This quantitative survey has been designed to document learner's perceptions of changes in their attitudes and behaviours with regard to IPC competencies as a result of IPE. Learners reflect back after completing the IPE experience and identify (in hindsight) where they perceive they were before and after the learning experience.

\section{W(e)Learn Assessment}

This_quantitative_instrument is_designed_to_align with the W(e)Learn framework http://wwww.ennovativesolution.com/WeLearn/!

Learners rate their experiences in an IPE program using the dimensions of IPE identified by the W(e)Learn framework (content, media, service, structure and outcomes).

\section{Learner Contract}

This qualitative tool has been created to help individual learners develop the core competencies needed to collaborate effectively with other healthcare professionals. Specifically, the contract will:

a) document how learners plan to develop their knowledge, skills and activities associated with IPC;

b)assist learners in identifying and documenting learning outcomes associated with the learning activities. 


\section{JRIPE}

315

Designing and operationalizing a toolkit

MacDonald, Archibald, Trumpower, Casimiro, Cragg, \& Jelley
Journal of Research in Interprofessional Practice and Education

This tool will facilitate learner's planning, monitoring, and assessment of their IPE experience.

\section{Learner Contract Exemplar}

The Learner Contract exemplar provides ideas, appropriate language, and suggestions for how to plan and implement strategies to facilitate and assess IPE activities. Facilitators may choose to share this tool with learners to guide them in their IPC planning or to use some or all of it to support their teaching.

\section{Team Contract}

This qualitative tool has been created to help teams work together effectively. Specifically, the contract will:

a) document how teams plan to develop knowledge, skills, and activities associated with (IPC); and

b)assist teams in identifying and documenting learning outcomes associated with the learning activities.

This tool will facilitate teams in planning, monitoring, and assessing their IPE experience.

\section{Team Contract Exemplar}

The Team Contract exemplar provides ideas, appropriate language, and suggestions for how to plan and implement strategies to facilitate and assess IPE activities. Facilitators may choose to share this tool with teams to guide them in their IPC planning or to use some or all of it to support their teaching.

\section{Program Description and Instrument Feedback Survey}

This brief survey asks about certain aspects of your IPE program(s). It also allows you to provide us with feedback about the instruments.

\section{Ethics Approval Notice}

This is a letter from the University of Ottawa's Social Sciences and Humanities Research Ethics Board (REB) confirming the ethical approval of this project. Your institution's own REB may require that you submit this letter along with your own application for ethics approval.

\section{Excel Data Entry Template}

This Excel file contains a separate worksheet for each of the IPE instruments. 


\section{JRIPE}

316

Designing and operationalizing a toolkit

MacDonald, Archibald, Trumpower, Casimiro, Cragg, \& Jelley

Journal of Research in Interprofessional Practice and Education

Vol. 1.3

December, 2010
Journal of Research in Interprofessional Practice and Education

\begin{tabular}{|c|c|}
\hline Enclosure & Description \\
\hline $\begin{array}{l}\text { ICCAS - Interprofessional } \\
\text { Collaborative Competencies } \\
\text { Attainment Survey }\end{array}$ & $\begin{array}{l}\text { This quantitative survey has been designed to document learner's perceptions of } \\
\text { changes in their attitudes and behaviours with regard to IPC competencies as a result } \\
\text { of IPE. Learners reflect back after completing the IPE experience and identify (in hind- } \\
\text { sight) where they perceive they were before and after the learning experience. }\end{array}$ \\
\hline W(e)Learn Assessment & $\begin{array}{l}\text { This quantitative instrument is designed to align with the W(e)Learn framework } \\
\text { http://www.ennovativesolution.com/WeLearn/. } \\
\text { Learners rate their experiences in an IPE program using the dimensions of IPE iden- } \\
\text { tified by the W(e)Learn framework (content, media, service, structure and out- } \\
\text { comes). }\end{array}$ \\
\hline Learner Contract & $\begin{array}{l}\text { This qualitative tool has been created to help individual learners develop the core } \\
\text { competencies needed to collaborate effectively with other healthcare professionals. } \\
\text { Specifically, the contract will: } \\
\text { a) document how learners plan to develop their knowledge, skills and activities } \\
\text { associated with IPC; } \\
\text { b) assist learners in identifying and documenting learning outcomes associated } \\
\text { with the learning activities. } \\
\text { This tool will facilitate learner's planning, monitoring, and assessment of their IPE } \\
\text { experience. }\end{array}$ \\
\hline Learner Contract Exemplar & $\begin{array}{l}\text { The Learner Contract exemplar provides ideas, appropriate language, and sugges- } \\
\text { tions for how to plan and implement strategies to facilitate and assess IPE activities. } \\
\text { Facilitators may choose to share this tool with learners to guide them in their IPC } \\
\text { planning or to use some or all of it to support their teaching. }\end{array}$ \\
\hline Team Contract & $\begin{array}{l}\text { This qualitative tool has been created to help teams work together effectively. } \\
\text { Specifically, the contract will: } \\
\text { a) document how teams plan to develop knowledge, skills, and activities associated } \\
\text { with (IPC); and } \\
\text { b) assist teams in identifying and documenting learning outcomes associated with } \\
\text { the learning activities. } \\
\text { This tool will facilitate teams in planning, monitoring, and assessing their IPE } \\
\text { experience. }\end{array}$ \\
\hline Team Contract Exemplar & $\begin{array}{l}\text { The Team Contract exemplar provides ideas, appropriate language, and suggestions } \\
\text { for how to plan and implement strategies to facilitate and assess IPE activities. } \\
\text { Facilitators may choose to share this tool with teams to guide them in their IPC } \\
\text { planning or to use some or all of it to support their teaching. }\end{array}$ \\
\hline $\begin{array}{l}\text { Program Description and } \\
\text { Instrument Feedback Survey }\end{array}$ & $\begin{array}{l}\text { This brief survey asks about certain aspects of your IPE program(s). It also allows } \\
\text { you to provide us with feedback about the instruments. }\end{array}$ \\
\hline Ethics Approval Notice & $\begin{array}{l}\text { This is a letter from the University of Ottawa's Social Sciences and Humanities } \\
\text { Research Ethics Board (REB) confirming the ethical approval of this project. Your } \\
\text { institution's own REB may require that you submit this letter along with your own } \\
\text { application for ethics approval. }\end{array}$ \\
\hline Excel Data Entry Template & This Excel file contains a separate worksheet for each of the IPE instruments. \\
\hline
\end{tabular}

